\title{
Stature estimation study based on pelvic and sacral morphometric among Malaysian population
}

\author{
Poh Soon Lai ${ }^{\text {* }}$ (D, Mohamad Helmee Mohamad Noor ${ }^{2}$ and Nurliza Abdullah
}

\begin{abstract}
Background: Virtual anthropology in estimating stature through multislice computed tomography scanning is important for forensic cases and mass disasters. Regression formulae generated directly from other post-cranial skeleton parts can be applied for estimating stature. Literatures have revealed that scoring of pelvic shape in both sexes is significantly correlated with stature. Hereafter, this study aims to correlate the pelvic and sacral morphometric with stature based on sex and ancestry among the Malaysian population from the selected samples of $373 \mathrm{CT}$ images at Kuala Lumpur Hospital. The three-dimensional pelvic girdles were first segmented from CT images through Mimics Research 17.0 software. Inter-landmark distances were measured with Microsoft 3D Builder and their respective indexes were computed.
\end{abstract}

Results: This study showed that the auricular lengths, ilium dimension and acetabulum were the most useful stature estimator at $R>0.5$. The combination of pelvic parameters, sacral parameters and indexes had contributed to a higher $R^{2}$ value of the regression models.

Conclusions: Pelvic morphometric was generally a better stature estimator compared to sacral morphometric. The population-specific formula produced from this study should only be realistic within the Malaysian population. This helps to enhance the existing references for stature estimation especially when incomplete human remains are discovered.

Keywords: Forensic anthropology, Pelvic, Sacrum, Stature estimation, Malaysian population

\section{Background}

Biological profiling in anthropological methodology encompasses estimation of sex (male and female), ancestry or geographical ancestry (African, European and Asian), skeletal stature and age-at-death estimation (Linda 2006). The advancement of virtual anthropology has been designated with multi-slice three dimensional (3D) rendered computed tomography (CT) scanning. This is easily available to most forensic anthropologists who are practicing in the forensic mortuary, for example

\footnotetext{
*Correspondence: roysonn1@hotmail.com

${ }^{1}$ Institute of Forensic Medicine Malaysia, Kuala Lumpur Hospital, Kuala

Lumpur, Malaysia

Full list of author information is available at the end of the article
}

at Kuala Lumpur Hospital, Malaysia (Khoo and Mohd Shah 2014).

Stature estimation was first steered during the middle of the eighteenth century by Jean-Joseph Sue and further established by Carl Pearson (Megan and Ann 2013). Living stature is demarcated as the maximum height reached during a person's lifetime and may be anticipated only after age, sex, and ancestry have been evaluated. This is due to varying levels of growth, skeletal degeneration, sexual dimorphism, and population variation (Megan and Ann 2013; Wiley 2016). Estimating stature is part of the identification process in mass disasters and forensic cases to assist the police in death investigation (Özaslan et al. 2003). 
Although both whole-limb-bone and whole-skeleton methods are usually utilised for stature estimation, nonetheless, it is restricted in situations where the complete bones may be absent and bodies are fragmentary (Wiley 2016). Hence, the remedy of this situation is by applying regression formula using the length of other body parts (Megan and Ann 2013; Wiley 2016). For example, stature estimation is well established by means of the length of long bones especially lower limbs (Wiley 2016). Regression formulae have also been calculated for estimating stature directly from cranium, vertebrae, clavicle, scapula, sternum, pelvis, foot, hand bones and other parts of the body since the early 1980s (Wiley 2016).

The pelvic girdle, as a part of the human appendicular skeletal system, consists of the paired pelvic bones or os coxae whereby is articulated anteriorly through the cartilaginous element at the pubic symphysis (Standring 2015). It is also articulated posteriorly with the sacrum as part of the axial skeleton at the inferior-most part of the vertebral column forming the pelvis as shown in Fig. 1.

Pelvic shape score is significantly correlated with the stature in both sexes among Hamann-Todd collection (Barbara and Philipp 2015). Taller individuals have a relatively higher and narrower pelvis with a more oval pelvic inlet and a more forward projecting symphysis compared to shorter individuals with rounder pelvic cavity (Barbara and Philipp 2015; Megan and Ann 2013). On average, taller persons have longer iliac blades and a shorter relative distance between the acetabula compared with shorter persons (Barbara and Philipp 2015; Wiley 2016). Both margins between iliac spines to ischial spines and iliac spines to ischial tuberosities are very strongly correlated with stature (Torimitsu et al. 2015). This correlation is stronger in males compared to females. This is also applicable to sacrum height and pubic symphysis length (Barbara and Philipp 2015; Pelin et al. 2005; Torimitsu et al. 2014, 2015).

On the other hand, there are also a few studies on sacrum height using the images of magnetic resonance imaging (MRI) and multi-slice CT applying for stature estimation (Hakki et al. 2011; Pelin et al. 2005; Torimitsu et al. 2014). As study showed that sacrum height in males is significantly higher than in females (Hakki et al. 2011; Torimitsu et al. 2014). The correlation between sacral height and the stature is reported as only significant in males (Hakki et al. 2011). In contrary, Torimitsu et al. (2014) reported a positive correlation in both sexes, however, all these studies revealed a comparatively moderate regression coefficient ranging from 0.4 to 0.6 only. Multiple regression equations could be designed from plenty of parameters to improve these regression coefficient, $R^{2}$ (Pelin et al. 2005).

In spite of numerous stature formulae that have been developed for worldwide populations, these equations cannot be applied in the Malaysian population as regression formulae are generally population specific. There is always the necessity for additional populationspecific reference data through regression theory and mathematical methods. Hence, this study aims to correlate the pelvic and sacral morphometric with stature based on sex and ancestry among the Malaysian population.

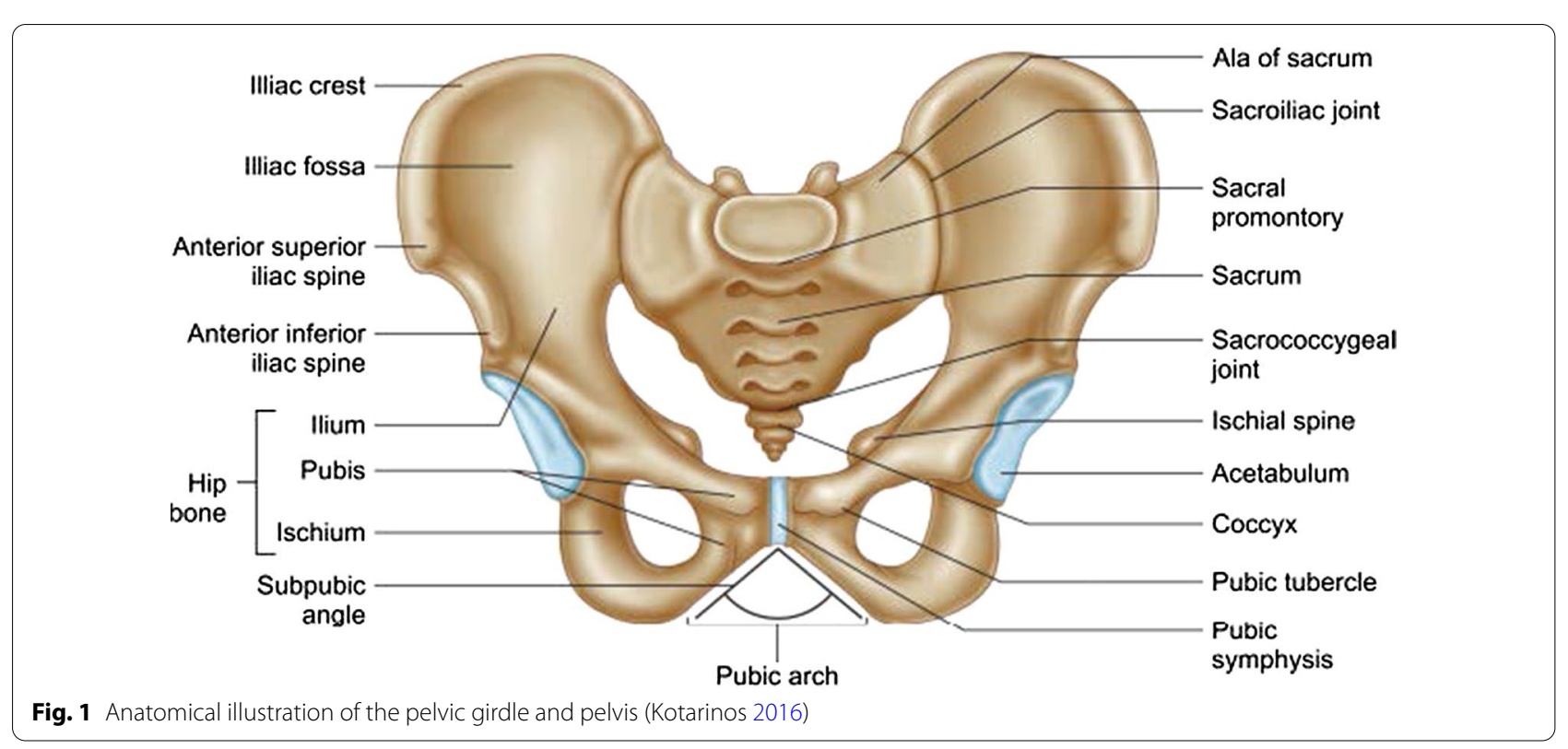




\section{Methods}

This was a retrospective cross-sectional study of the pelvic girdle. A total of $373 \mathrm{CT}$ Scan Digital Imaging and Communications in Medicine (DICOM) folders from year 2010 to 2018 that stored in Picture Archiving and Communication Systems (PACS) were first retrieved retrospectively from living patient subjects of Radiology Department as well as postmortem subjects of National Institute of Forensic Medicine (NIFM) in Kuala Lumpur Hospital (HKL). These images were copied into encrypted external hard drive.

Postmortem subjects have been scanned by using 2-blocks CT for the whole body using a Toshiba

Table 1 Subject distribution across sex, age and ancestry subgroups

\begin{tabular}{|c|c|c|c|c|c|}
\hline \multirow[t]{2}{*}{ Age groups } & \multirow[t]{2}{*}{ Sex groups } & \multicolumn{3}{|c|}{ Ancestry subgroups } & \multirow[t]{2}{*}{ Total } \\
\hline & & Malay & Chinese & Indian & \\
\hline \multirow[t]{2}{*}{ 10-19 } & Male & 9 & 9 & 9 & 27 \\
\hline & Female & 9 & 8 & 6 & 23 \\
\hline \multirow[t]{2}{*}{ 20-29 } & Male & 9 & 9 & 9 & 27 \\
\hline & Female & 9 & 9 & 9 & 27 \\
\hline \multirow[t]{2}{*}{$30-39$} & Male & 9 & 9 & 9 & 27 \\
\hline & Female & 9 & 9 & 9 & 27 \\
\hline \multirow[t]{2}{*}{$40-49$} & Male & 9 & 9 & 9 & 27 \\
\hline & Female & 9 & 9 & 9 & 27 \\
\hline \multirow[t]{2}{*}{$50-59$} & Male & 9 & 9 & 9 & 27 \\
\hline & Female & 9 & 9 & 9 & 27 \\
\hline \multirow[t]{2}{*}{$60-69$} & Male & 9 & 9 & 9 & 27 \\
\hline & Female & 9 & 9 & 9 & 27 \\
\hline \multirow[t]{2}{*}{ 70-79 } & Male & 9 & 9 & 8 & 26 \\
\hline & Female & 9 & 9 & 9 & 27 \\
\hline \multirow[t]{3}{*}{ Subtotal } & Male & 63 & 63 & 62 & 188 \\
\hline & Female & 63 & 62 & 60 & 185 \\
\hline & Total & 126 & 125 & 122 & 373 \\
\hline
\end{tabular}

Aquilion 64 Postmortem Multi-slice CT scanner whilst living patient subjects have been selected from their diagnostic scans including the $\mathrm{CT}$ abdomen, $\mathrm{CT}$ pelvic and CT urography with $1.0 \mathrm{~mm}$ resolution in average. Subjects were carefully chosen based on sex subgroups (Male and Female) and ancestry subgroups (Malay, Chinese and Indian) for each decade subgroup from 10 to 79 years old as summarised in Table 1 . The equal distribution of subjects could counterweight the variability of the confounders including sex, age and ancestry in this study.

The demographic data likewise sex, age, ancestry and height were traced from the Forensic Medicine Information System (FMIS) and Patient Appointment System (PAS). The height in centimetre $(\mathrm{cm})$ for postmortem subjects were measured during the autopsy examination and retrieved from the postmortem reports. On the contrary, the heights for living patients were retrieved from the registration forms or confirmed by contacting the patients. Data collection for living stature is collected from various sources that are likely resulting in some error compared to cadaver stature but this will not significantly affect the results (Wilson et al. 2010). Cases were excluded if the history pointed the conditions that could have affected bone morphology of the pelvic girdle likewise fracture, burning, anomalies.

The pelvic and sacrum bones were first viewed and segmented likewise sex, age, ancestry and height by using software Mimic Research 17.0, available at the School of Dental Sciences, Universiti Sains Malaysia. Linear measurements including seven sacral parameters and eight pelvic measurements Tables 2, 3 and 4, Figs. 2 and 3 were taken in centimeter $(\mathrm{cm})$ at 2 decimal points via the software 3D Builder (Garvin and Severa 2019). The measurements were taken twice to satisfy the intra-observer error analysis for all the subjects. Relative technical error of measurement (TEM) for

Table 2 Definition and description of sacrum parameters adopted from Kanika et al. (2011) and Shreekrishna et al. (2013)

\begin{tabular}{|c|c|c|}
\hline No & Parameter(s) & Description \\
\hline P1S & Sacral basal width & $\begin{array}{l}\text { Maximum transverse midpoint distance of the superior surface of sacrum that comprising of the two } \\
\text { alae }\end{array}$ \\
\hline $\mathrm{P} 2 \mathrm{~S}$ & Transverse diameter S1 body & Maximum transverse midpoint diameter of the articular surface of the body of first sacral vertebra (S1) \\
\hline P3S & Anteroposterior (A-P) diameter S1 body & $\begin{array}{l}\text { Antero-posterior distance from the midpoint of sacral promontory up to the midpoint on the posterior } \\
\text { border of S1 body }\end{array}$ \\
\hline P4S & Average ala width & Maximum straight distance of the sacral ala from the right transverse diameter of the S1 body \\
\hline P5S & Sacral height & The midpoint of the sacral promontory to the middle of antero-inferior border of the fifth sacral vertebra \\
\hline P6S & Average auricular surface length & Maximum distance of the superior-inferior inner border of auricular surface on lateral aspect of sacrum \\
\hline P7S & Average ala A-P length & $\begin{array}{l}\text { Antero-posterior distance from the lateral posterior most point up to lateral anterior most point on the } \\
\text { superior border of the ala }\end{array}$ \\
\hline
\end{tabular}


Table 3 Definition and description of sacrum indexes adopted from Kanika et al. (2011) and Shreekrishna et al. (2013)

\begin{tabular}{|c|c|c|c|}
\hline No & Index(es) & Description & Formula \\
\hline I1S & Sacral index & Ratio of sacral basal width to sacral height (sacral mid-ventral straight length) (\%) & $\frac{\mathrm{P} 1}{\mathrm{P} 5}$ \\
\hline $12 \mathrm{~S}$ & Corporobasal index & Ratio of transverse diameter of S1 body (corpus width) to sacral basal width of S1 (\%) & $\frac{\mathrm{P} 2}{\mathrm{P} 1}$ \\
\hline $13 S$ & S1 body index & Ratio of anteroposterior (A-P) diameter to transverse diameter of S1 body (\%) & $\frac{\mathrm{P} 3}{\mathrm{P} 2}$ \\
\hline 145 & Alar base-wing index & Ratio of average bilateral ala width to transverse diameter of S1 body (\%) & $\frac{\mathrm{P} 4}{\mathrm{P} 2}$ \\
\hline $15 S$ & Auricular index & Ratio of average bilateral auricular surface length to sacral basal width (\%) & $\frac{\mathrm{P} 6}{\mathrm{P} 1}$ \\
\hline $16 \mathrm{~S}$ & Alar diagonal index & Ratio of average bilateral ala width to average bilateral ala anteroposterior (A-P) length (\%) & $\frac{\mathrm{P} 4}{\mathrm{P} 7}$ \\
\hline
\end{tabular}

Table 4 Definition and description of pelvic girdle parameters modified based on Lia et al. (2013)

\begin{tabular}{|c|c|c|}
\hline No & Parameter(s) & Description \\
\hline P1P & Ilium transverse length & Transverse diameter width of two apex of the antero-superior right and left iliac spine \\
\hline $\mathrm{P} 2 \mathrm{P}$ & Pubic inlet transverse diameter & Maximum central distance of the widest margins of the pubic inlet \\
\hline P3P & Average pubic inlet longitudinal diameter & $\begin{array}{l}\text { Distance from the midpoint of sacral body (S1) to the most superior point on the superior edge of the } \\
\text { medial aspect of the pubic symphysis }\end{array}$ \\
\hline P4P & Average pubic height & $\begin{array}{l}\text { Distance between the most superior and most inferior point on the inferior edge of the medial aspect } \\
\text { of the pubic symphysis }\end{array}$ \\
\hline P5P & Average ilium breadth & Distance between apex of the postero-superior iliac spine and apex of the antero-superior iliac spine \\
\hline P6P & Average ilium height & Distance between the most superior point of the iliac crest and the farthest point of ischial curve \\
\hline P7P & Average acetabulum width & $\begin{array}{l}\text { Maximum diameter of the points on the acetabulum margin corresponding to where ilium and ilio- } \\
\text { pubic ramus meet }\end{array}$ \\
\hline P8P & Average acetabulum height & $\begin{array}{l}\text { Maximum diameter of the most inferior points of the anterior end of the lunate surface of the } \\
\text { acetabulum }\end{array}$ \\
\hline
\end{tabular}

each parameter, which was acceptable if less than $5 \%$, was calculated using Eqs. 1 and 2 (Perini et al. 2005). The calculation was shown in the equations below:

$$
\text { Absolute TEM }=\sqrt{\frac{\Sigma d_{i}^{2}}{2 n}}
$$

where $\Sigma d^{2}=$ summation of deviations raised to the second power, $n=$ number of subjects measures, $i=$ index of the case having values $1,2, \ldots, n$

$$
\text { Relative TEM }=\frac{\mathrm{TEM}}{\mathrm{VAV}} \times 100
$$

where TEM = absolute TEM from Eq. 1 expressed in \%, $\mathrm{VAV}=$ average value of the parameters and indexes.

Extreme outliers had been removed from this study in order to eliminate the limitation of the analysis. The Kolmogorov-Smirnov test $(N>100)$ was first conducted to determine normality at $p>0.05$ of all the parameters. Correlation analyses were performed by using Statistical Package for the Social Sciences (SPSS) version 24 to determine the relationship of pelvic and sacral morphometrics with the stature of the subjects according to sex and ancestry. The regression analyses were then performed by using well-correlated parameters and then regression coefficients were acknowledged for each generated formula.

Further validation analysis of the stature regression equations was conducted by using holdout 56 subjects equally in both sexes, i.e. $15 \%$ separated from the total subjects (Mahakkanukrauh et al. 2011). This meant that the remaining $85 \%$ of the total subjects were utilised to generate new regression formulae from this study and to be tested by using the above mentioned holdout subjects. Validation test on the holdout subjects were performed by estimating the stature for each individual and comparing it to their actual stature. Afterward, the mean absolute deviation (MAD) and mean squared error (MSE) were computed.

\section{Results}

The descriptive statistics for the stature and normality were assumed as shown in Table 5 . The stature of the selected subjects were normally distributed based on the histogram as plotted in Fig. 4. This proves that the stature distribution were unbiased during subject selection and acceptable for statistical analysis. There was a total of eight pelvic parameters and seven sacral parameters measured in this study to generate six indexes of sacral morphometric analysis for biological profiling. 

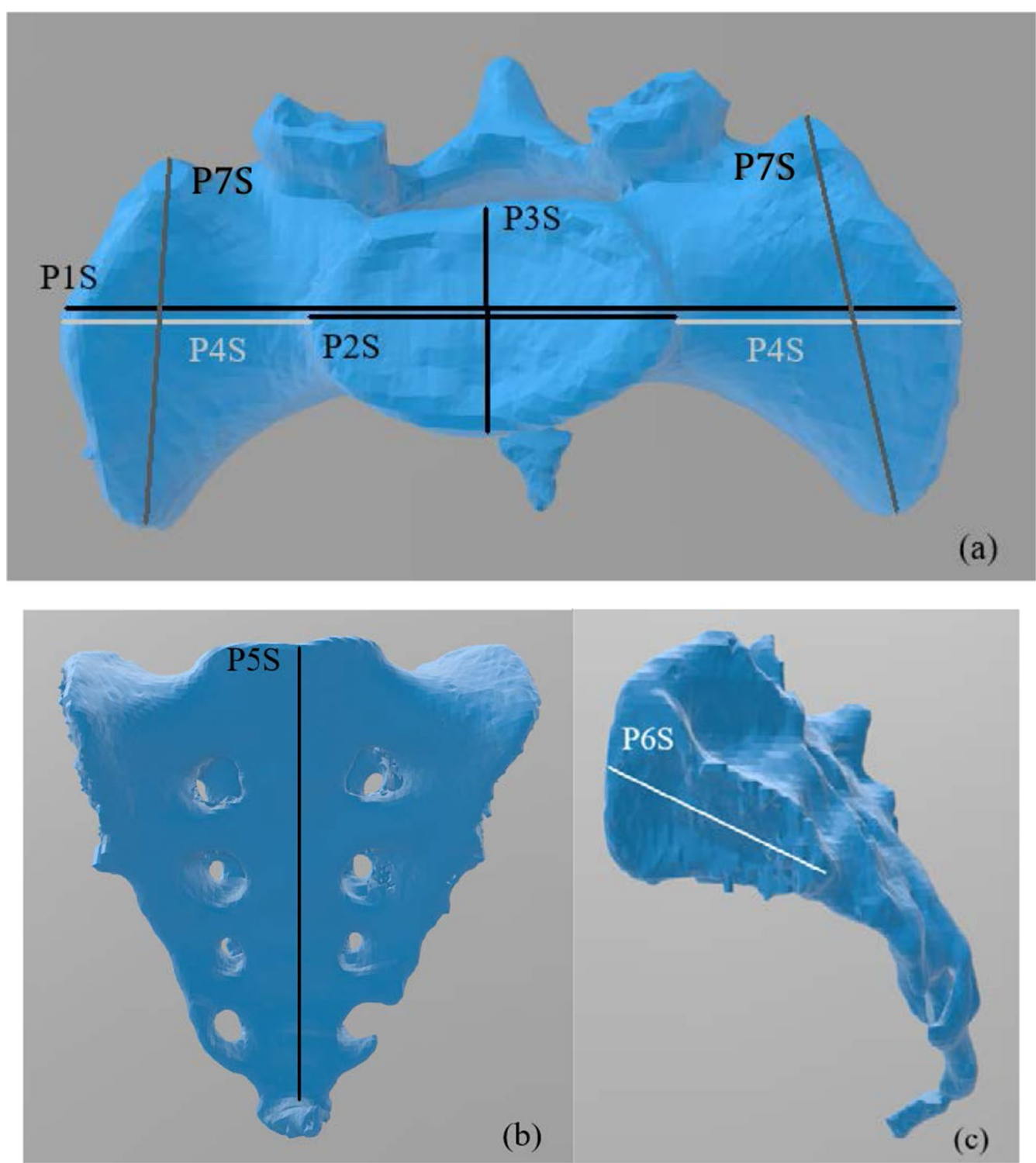

Fig. 2 Inter-landmark distances and parameters shown on the sacrum at superior view (a), anterior view (b) and lateral view (c). Screenshots obtained from Microsoft 3D Builder software

Descriptive statistics for the overall selected subjects had been listed in Table 6. Kolmogorov-Smirnov (K-S) test showed that normality was assumed at $p>0.05$ for all the parameters and indexes except alae A-P lengths (P7S), ilium transverse length and breadth (P1P \& P5P), pubic inlet longitudinal diameter (P3P) and acetabulum dimensions (P7P \& P8P). However, the boxplots of these parameters were normally distributed with the central spread of the parameter measurements.

From the results shown in Table 7, a significant difference between the right side and the left side of the pelvic bones and sacrum existed $(p<0.05)$ except ilium height and acetabulum width. These findings concurred with Boulay et al. (2006) whereby pelvic asymmetry was encountered especially in the area of iliac blades, iliac breadth and superior lunate surface of acetabulum. As such, both sides of the bones were required to be measured so as to consider the bilateral asymmetry of the pelvic girdle and the average of both sides shall be used for index calculations.

Kevin Norton's and Tim Old's methodology were applied by computing the technical error of measurements (TEM) as well as the coefficient of reliability in several previous studies (Goto and Nicholas 2007; 


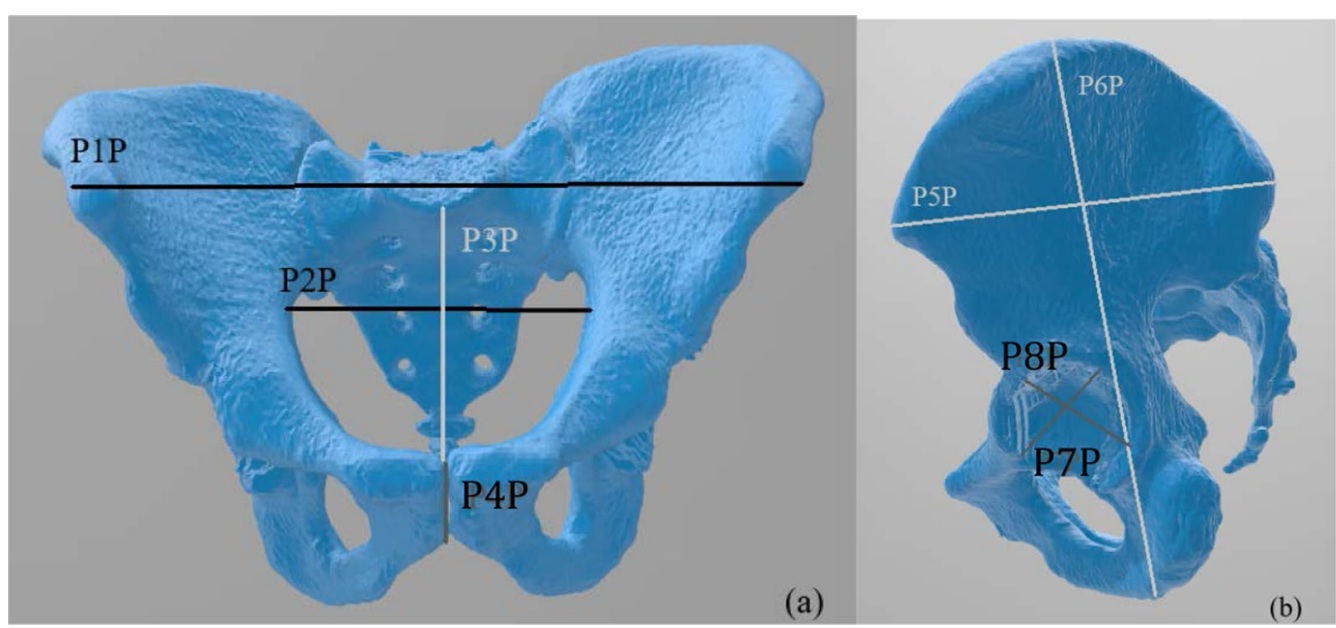

Fig. 3 Inter-landmark distances shown on the pelvic at anterior view (a) and lateral view (b). Screenshots obtained from Microsoft 3D Builder software

Table 5 Descriptive statistics for age and stature of subjects selected

\begin{tabular}{llllll}
\hline No & $\boldsymbol{N}$ & Minimum-Maximum & Mean \pm SE & SD & $\begin{array}{l}\text { K-S test } \\
\boldsymbol{p} \text { value }\end{array}$ \\
\hline Stature $\quad 361$ & $125.00-186.00$ & $161.26 \pm 0.48$ & 9.20 & $0.200^{*}$ \\
\hline $\begin{array}{l}\text { Unit in centimetre }(\mathrm{cm}) \\
{ }^{*} p>0.05\end{array}$ & & & \\
\end{tabular}

Jamaiyah et al. 2010; Perini et al. 2005). In this study, duplicate readings for each of the parameters were measured by both Observer 1 and Observer 2 to compensate for the observer errors. There was no significant intra-observer and inter-observer error based on the paired sample t-test at $p>0.05$ with low relative TEM at below 5\% and good reliability at above 0.8 . Hence, these had assertively revealed that the morphometric data generated from the landmarking points chosen were precise and reliable for further analysis.

A total of 186 males and 175 females have been selected for the stature estimation based on the parameters and indexes as listed in Table 8 by using correlation and regression analysis. Sacral basal width (P1S), S1 body diameters (P2S \& P3S), sacral height (P5S), alae A-P lengths (P7S), S1 body index (I3S) and auricular index (I5S) had a relatively significant positive correlation with stature at $R<0.500$. However, the sacral index (I1S) and alae diagonal index (I6S) had a relatively significant negative correlation with stature at $R<-0.200$. All these parameters were considered in combination for regression formula with higher $R$-values as listed in Table 9.
Table 6 Descriptive statistics for parameters and indexes of pelvic and sacral morphometric

\begin{tabular}{lllrrl}
\hline No & $\boldsymbol{N}$ & Minimum-Maximum & Mean \pm SE & \multicolumn{1}{c}{ SD } & $\begin{array}{l}\text { K-S test } \\
\boldsymbol{p} \text { value }\end{array}$ \\
\hline P1S & 363 & $9.64-12.59$ & $11.01 \pm 0.03$ & 0.58 & $0.061^{*}$ \\
P2S & 373 & $2.83-7.14$ & $4.76 \pm 0.03$ & 0.67 & $0.200^{*}$ \\
P3S & 367 & $1.99-3.93$ & $3.06 \pm 0.02$ & 0.32 & $0.170^{*}$ \\
P4S & 373 & $1.59-4.39$ & $3.11 \pm 0.02$ & 0.37 & $0.200^{*}$ \\
P5S & 373 & $6.59-12.59$ & $10.14 \pm 0.05$ & 0.99 & $0.200^{*}$ \\
P6S & 373 & $4.00-7.42$ & $5.46 \pm 0.03$ & 0.58 & $0.060^{*}$ \\
P7S & 365 & $3.87-6.52$ & $5.19 \pm 0.03$ & 0.52 & 0.024 \\
I1S & 359 & $84.66-137.50$ & $108.64 \pm 0.51$ & 9.69 & $0.077^{*}$ \\
I2S & 363 & $25.84-59.95$ & $43.45 \pm 0.31$ & 5.85 & $0.172^{*}$ \\
I3S & 365 & $43.64-86.85$ & $64.55 \pm 0.34$ & 6.50 & $0.200^{*}$ \\
I4S & 367 & $33.89-112.50$ & $66.44 \pm 0.72$ & 13.88 & $0.069^{*}$ \\
I5S & 363 & $35.34-65.96$ & $49.95 \pm 0.28$ & 5.37 & $0.200^{*}$ \\
I6S & 358 & $42.27-85.65$ & $59.87 \pm 0.44$ & 8.30 & $0.184^{*}$ \\
P1P & 360 & $15.29-26.97$ & $22.79 \pm 0.10$ & 1.81 & 0.032 \\
P2P & 363 & $7.56-14.01$ & $11.80 \pm 0.05$ & 0.96 & $0.064^{*}$ \\
P3P & 365 & $8.60-14.02$ & $11.35 \pm 0.06$ & 1.07 & 0.042 \\
P4P & 371 & $1.82-4.59$ & $3.11 \pm 0.02$ & 0.40 & $0.200^{*}$ \\
P5P & 370 & $10.18-17.22$ & $14.58 \pm 0.05$ & 1.01 & 0.000 \\
P6P & 366 & $14.90-23.96$ & $19.56 \pm 0.07$ & 1.38 & $0.200^{*}$ \\
P7P & 372 & $3.86-5.59$ & $4.73 \pm 0.02$ & 0.37 & 0.001 \\
P8P & 372 & $3.89-5.75$ & $4.77 \pm 0.02$ & 0.37 & 0.014 \\
\hline Unt & & & & &
\end{tabular}

Unit in centimetre $(\mathrm{cm})$

* $p>0.05$

In addition, auricular lengths (P6S) were the most useful stature estimator at positive correlation coefficient, $R>0.500$ at $p<0.001$. Despite that, Zhan et al. (2018) had 


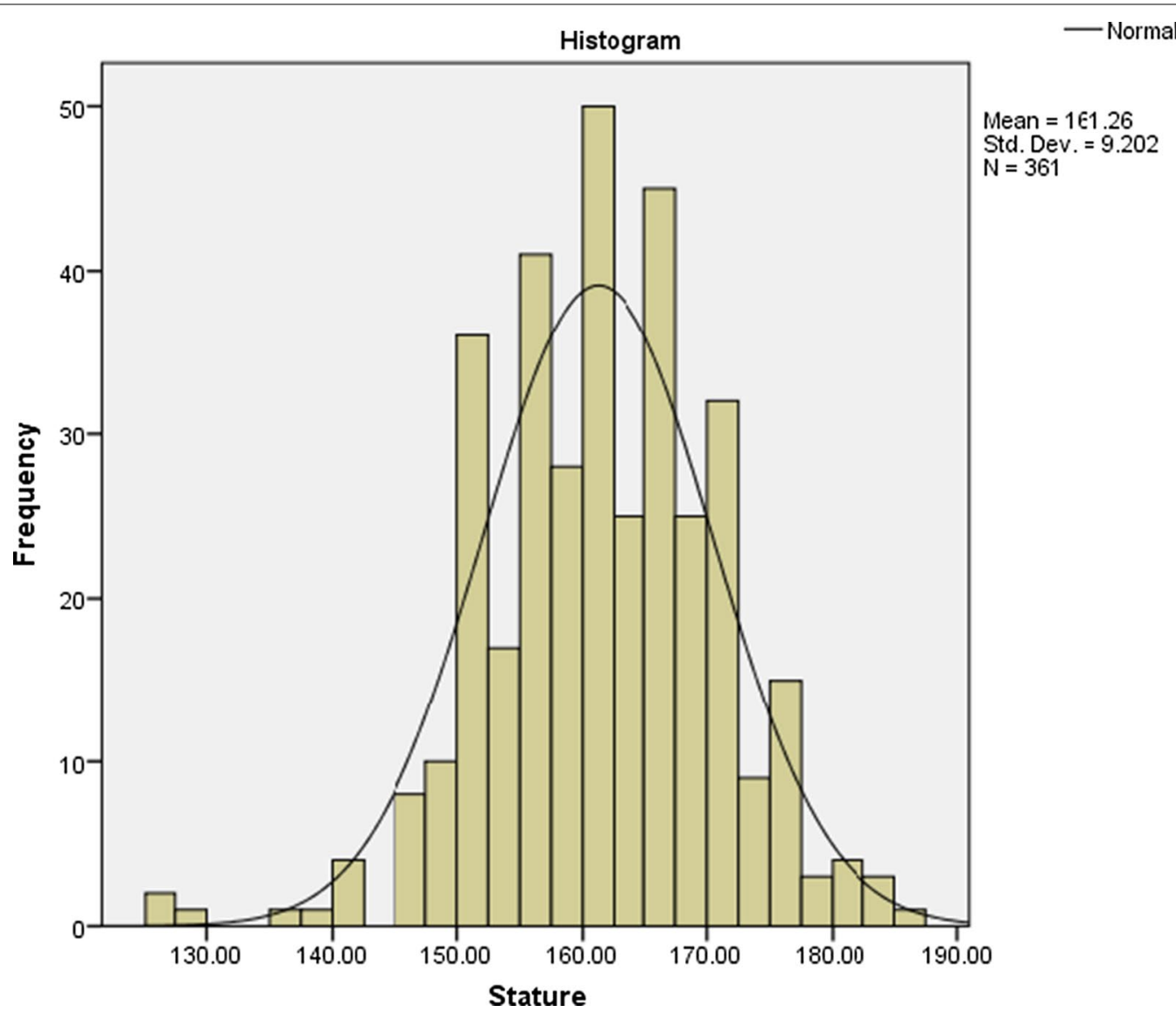

Fig. 4 Histogram for stature distribution of the selected subjects

reported relatively lower $R$-value for auricular length and A-P diameter of S1 body (P3S) but higher in sacral basal width (P1S) among Chinese population in China compared to the Malaysian population. Having said that, the $R$-value determined in this study for P2S and P5S had relatively lower $R$-value compared to the other studies

Table 7 Paired sample statistics for symmetry analysis of pelvic and sacral morphometrics

\begin{tabular}{llllrr}
\hline No & $\boldsymbol{N}$ & $\begin{array}{l}\text { Paired } \\
\text { samples } \\
\text { correlation }\end{array}$ & $\begin{array}{l}\text { Correlation } \\
\boldsymbol{p} \text { value }\end{array}$ & t value & $\begin{array}{l}\text { Paired } \\
\text { samples } \\
\boldsymbol{p} \text { value }\end{array}$ \\
\hline Pair 1: P4S & 372 & 0.757 & $<0.001$ & 2.045 & $0.042^{*}$ \\
Pair 2: P6S & 373 & 0.853 & $<0.001$ & -3.916 & $<0.001^{*}$ \\
Pair 3: P7S & 363 & 0.835 & $<0.001$ & 2.196 & $0.029^{*}$ \\
Pair 1: P3P & 363 & 0.997 & $<0.001$ & -3.501 & $0.001^{*}$ \\
Pair 2: P4P & 371 & 0.955 & $<0.001$ & 3.225 & $0.001^{*}$ \\
Pair 3: P5P & 364 & 0.936 & $<0.001$ & 3.992 & $<0.001^{*}$ \\
Pair 4: P6P & 361 & 0.977 & $<0.001$ & -0.629 & 0.530 \\
Pair 5: P7P & 367 & 0.866 & $<0.001$ & 0.376 & 0.707 \\
Pair 6: P8P & 367 & 0.876 & $<0.001$ & 21.569 & $<0.001^{*}$ \\
\hline
\end{tabular}

(Lai et al. 2020). This had shown that the regression formula was totally dependent on the study population in their respective studies. The population-specific formula produced from this study should only be applied to the Malaysian population especially the three main ethnicities that were included in this study.

From the Table 10, ilium dimensions (P5P \& P6P) and acetabulum dimensions (P7P \& P8P) had a greater significant positive correlation with stature at $R>0.500$ with even lower MAD and MSE compared to sacral morphometric within acceptable accuracy within SEE range. However, the pubic inlet dimensions (P2P \& P3P) had no significant correlation with stature at $p>0.05$. Subsequently, all these parameters with significant correlation were considered in combination for regression formula with higher $R$-values at $R=0.822$ and smaller SEE, MAD and MSE as listed in Table 11.

Further validation analysis of the regression formulae was conducted by using holdout 28 males and 28 females. The remaining $85 \%$ of the total subjects were used to generate new regression formulae for each parameters and indexes. Estimated stature from the 
Table 8 Correlation and regression statistics for individual parameters and indexes of sacral morphometric against stature in validation analysis (Lai et al. 2020)

\begin{tabular}{|c|c|c|c|c|c|c|c|c|}
\hline No & $N$ & Regression formula & SEE & $R$ value & $R$ square & $\begin{array}{l}\text { Mean Abs } \\
\text { deviation }\end{array}$ & MSE & AWR (\%) \\
\hline P1S & 297 & $131.903+2.711(\mathrm{P} 1 \mathrm{~S})$ & 8.714 & $0.178^{*}$ & $0.032^{*}$ & 6.759 & 64.648 & 75.00 \\
\hline P2S & 305 & $152.298+1.900(\mathrm{P} 2 \mathrm{~S})$ & 9.305 & $0.143^{*}$ & $0.020^{*}$ & 6.550 & 62.834 & 76.79 \\
\hline P3S & 299 & $126.885+11.304(\mathrm{P} 3 \mathrm{~S})$ & 8.488 & $0.393^{*}$ & $0.154^{*}$ & 4.988 & 40.279 & 87.50 \\
\hline P4S & 305 & $155.764+1.794(\mathrm{P} 4 \mathrm{~S})$ & 9.373 & -0.078 & 0.006 & 6.815 & 67.296 & 71.43 \\
\hline P4S' & 304 & $153.663+2.500\left(\mathrm{P}^{\prime} \mathrm{S}^{\prime}\right)$ & 9.342 & -0.109 & 0.012 & 6.920 & 68.399 & 71.43 \\
\hline P5S & 305 & $125.401+3.531(\mathrm{P} 5 \mathrm{~S})$ & 8.739 & $0.369^{*}$ & $0.136^{*}$ & 7.185 & 72.318 & 71.43 \\
\hline P6S & 305 & $115.031+8.504(\mathrm{P} 6 \mathrm{~S})$ & 7.973 & $0.530^{*}$ & $0.281 *$ & 5.719 & 48.094 & 78.57 \\
\hline P6S' & 305 & $114.619+8.480\left(\mathrm{P}^{\prime} \mathrm{S}^{\prime}\right)$ & 7.813 & $0.556^{*}$ & $0.309 *$ & 5.210 & 39.879 & 78.57 \\
\hline P7S & 296 & $141.601+3.813(\mathrm{P} 7 \mathrm{~S})$ & 8.890 & $0.231^{*}$ & $0.054^{*}$ & 6.596 & 61.576 & 76.79 \\
\hline P7S' & 296 & $142.825+3.612\left(\mathrm{P}^{\prime} \mathrm{S}^{\prime}\right)$ & 8.908 & $0.213^{*}$ & $0.045^{*}$ & 6.515 & 61.074 & 78.57 \\
\hline $11 \mathrm{~S}$ & 293 & $185.969-0.224(11 S)$ & 8.656 & $-0.235^{*}$ & $0.055^{*}$ & 7.064 & 71.343 & 67.86 \\
\hline I2S & 297 & $161.977-0.004(12 S)$ & 8.855 & -0.003 & 0.000 & 6.777 & 67.042 & 67.86 \\
\hline I3S & 297 & $138.759+0.353(13 S)$ & 8.955 & $0.252^{*}$ & $0.064^{*}$ & 6.118 & 57.711 & 80.36 \\
\hline 145 & 299 & $162.858-0.022(14 S)$ & 9.463 & -0.033 & 0.001 & 6.669 & 65.328 & 75.00 \\
\hline $15 \mathrm{~S}$ & 297 & $127.861+0.679(15 S)$ & 8.081 & $0.409 *$ & $0.167^{*}$ & 5.823 & 50.828 & 82.14 \\
\hline $16 \mathrm{~S}$ & 290 & $169.042-0.126(165)$ & 9.095 & $-0.118^{*}$ & $0.014^{*}$ & 6.536 & 62.600 & 75.00 \\
\hline
\end{tabular}

Unit in centimetre $(\mathrm{cm})$

SEE represents the standard error of estimation for the generated regression formula; $R$ value represents the Pearson correlation coefficient; MSE represents mean squared error; AWR represents the accuracy percentage of estimated stature within SEE range compared to actual stature

Strong correlation results are in bold

${ }^{*} p<0.05$

'Left side of the measurement.

Table 9 Correlation and regression statistics for combination of parameters and indexes of sacral morphometric against stature in validation analysis

\begin{tabular}{|c|c|c|c|c|c|c|c|c|}
\hline$N$ & Regression formula & SEE & $R$ Value & $R$ Square & $\begin{array}{l}\text { Adjusted } R \\
\text { Square }\end{array}$ & $\begin{array}{l}\text { Mean Abs } \\
\text { Deviation }\end{array}$ & MSE & AWR (\%) \\
\hline 279 & $122.360-0.059^{*} \mid 1 \mathbf{S}+0.3773^{*} \mathbf{I 3 S}+0.575^{*} \mathbf{I} \mathbf{S}-0.116^{*} \mathbf{I 6 S}$ & 7.901 & $0.486^{*}$ & $0.237^{*}$ & $0.225^{*}$ & 5.397 & 46.737 & 80.36 \\
\hline 286 & $\begin{array}{l}90.117+1.008^{*} \mathbf{P} 1 \mathbf{S}-5.061^{*} \mathbf{P} 2 \mathbf{S}+9.275^{*} \mathbf{P} 3 \mathbf{S}+0.718^{*} \mathbf{P} 5 \mathbf{S} \\
\quad+2.107^{*} \mathbf{P} 6 \mathbf{S}+4.726^{*} \mathbf{P} 6 \mathbf{S}^{\prime}+3.153^{*} \mathbf{P} 7 \mathbf{S}-0.999^{*} \mathbf{P} 7 \mathbf{S}^{\prime}\end{array}$ & 7.138 & $0.615^{*}$ & $0.378^{*}$ & $0.360^{*}$ & 4.836 & 36.191 & 76.79 \\
\hline 277 & $\begin{array}{l}155.927-7.098^{*} \mathbf{P} 1 \mathbf{S}-6.073^{*} \mathbf{P} 2 \mathrm{~S}+9.397^{*} \mathbf{P} 3 \mathbf{S}+ \\
3.262^{*} \mathbf{P} 5 \mathbf{S}+9.258^{*} \mathbf{P} 6 \mathrm{~S}+12.337^{*} \mathbf{P} 6 \mathbf{S}^{\prime}+1.586^{*} \mathbf{P} 7 \mathbf{S}-1.782 \\
{ }^{*} \mathbf{P} 7 \mathbf{S}^{\prime}+0.213^{*} \mathbf{I} \mathbf{S}+0.016^{*} \mathbf{I} \mathbf{S}-1.620^{*} \mathbf{I 5 S}-0.168^{*} \mathbf{I} \mathbf{S}\end{array}$ & 7.112 & $0.633^{*}$ & $0.401^{*}$ & $0.374^{*}$ & 4.942 & 37.317 & 76.79 \\
\hline
\end{tabular}

Unit in centimetre $(\mathrm{cm})$

SEE represents the standard error of estimation for the generated regression formula; $R$ value represents the Pearson correlation coefficient; MSE represents mean squared error; AWR represents the accuracy percentage of estimated stature within SEE range compared to actual stature

${ }^{*} p<0.05$

'Left side of the measurement

generated formulae was compared to the actual stature of the holdout subjects and the mean absolute deviation (MAD) were ranging from 4.988 to $7.185 \mathrm{~cm}$ in which lower than the standard of estimation error (SEE) of the respective regression formulae. Stature estimation based on anteroposterior diameter of S1 body (P3S) had achieved lowest MAD and mean squared error (MSE) with highest accuracy at $87.50 \%$ within SEE range, followed by auricular length (P6S) though with slightly lower accuracy within SEE range.

\section{Discussion}

Generally, forensic anthropologists are more likely to be measuring dry bones rather than extracting measurements from CT data. There may also have some occasions whenever a mortuary receives an unknown case 
Table 10 Correlation and regression statistics for individual parameters of pelvic morphometric against stature

\begin{tabular}{|c|c|c|c|c|c|c|c|c|}
\hline No & $N$ & Regression formula & SEE & $R$ Value & $R$ square & $\begin{array}{l}\text { Mean Abs } \\
\text { deviation }\end{array}$ & MSE & AWR (\%) \\
\hline P1P & 292 & $125.219+1.594(\mathrm{P} 1 \mathrm{P})$ & 8.701 & $0.321^{*}$ & $0.103^{*}$ & 6.946 & 70.730 & 71.43 \\
\hline P2P & 295 & $155.594+0.512(\mathrm{P} 2 \mathrm{P})$ & 9.144 & 0.053 & 0.003 & 6.711 & 64.435 & 67.86 \\
\hline P3P & 297 & $156.393+0.463($ P3P) & 9.127 & 0.056 & 0.003 & 6.597 & 62.706 & 75.00 \\
\hline P4P & 303 & $129.591+10.187(\mathrm{P} 4 \mathrm{P})$ & 8.481 & $0.434^{*}$ & $0.188^{*}$ & 6.018 & 50.969 & 78.57 \\
\hline P5P & 302 & $78.846+5.650(\mathrm{P} 5 \mathrm{P})$ & 7.480 & $0.606^{*}$ & $0.367^{*}$ & 5.647 & 49.003 & 76.79 \\
\hline P6P & 300 & $57.536+5.303(\mathrm{P} 6 \mathrm{P})$ & 5.749 & $0.791^{*}$ & $0.625^{*}$ & 4.175 & 25.729 & 73.21 \\
\hline P7P & 304 & $83.860+16.340(P 7 P)$ & 7.089 & $0.658^{*}$ & $0.434^{*}$ & 4.209 & 28.309 & 82.14 \\
\hline P8P & 304 & $82.142+16.546(\mathrm{P} 8 \mathrm{P})$ & 7.158 & $0.650^{*}$ & $0.423^{*}$ & 4.470 & 31.673 & 82.14 \\
\hline
\end{tabular}

Unit in centimetre $(\mathrm{cm})$

SEE represents the standard error of estimation for the generated regression formula; $R$ value represents the Pearson correlation coefficient; Sig. value represents the significant values of the regression ANOVA corresponding to the F value

${ }^{*} p<0.05$

Table 11 Correlation and regression statistics for combination of pelvic morphometric against stature

\begin{tabular}{|c|c|c|c|c|c|c|c|c|}
\hline$N$ & Regression Formula & SEE & $R$ Value & $R$ Square & Adjusted $R$ Square & Mean Abs Deviation & MSE & AWR (\%) \\
\hline 289 & $\begin{array}{l}55.107-0.396^{*} \mathbf{P} 1 \mathbf{P}-1.737^{*} \mathbf{P} 4 \mathbf{P}+1.512^{*} \mathbf{P} 5 \mathbf{P}+4.4 \\
\text { 03*P6P+2.868*P7P }-0.184^{*} \mathbf{P} 8 \mathbf{P}\end{array}$ & 5.266 & 0.822 & 0.676 & 0.669 & 3.955 & 24.100 & 71.43 \\
\hline
\end{tabular}

Unit in centimetre $(\mathrm{cm})$

SEE represents standard error of estimation for the generated regression formula; $R$ value represents the Pearson correlation coefficient; Sig. value represents the significant values of the regression ANOVA corresponding to the F value

Table 12 Comparison of estimated stature by using formulae from different studies in validation analysis

\begin{tabular}{|c|c|c|c|c|c|c|}
\hline \multicolumn{4}{|c|}{ Transverse diameter S1 body (P2S) } & \multicolumn{3}{|c|}{ Sacral height (P5S) } \\
\hline Regression formula & $\begin{array}{l}\text { Mean Abs } \\
\text { deviation }\end{array}$ & $\begin{array}{l}\text { Mean squared } \\
\text { error }\end{array}$ & AWR (\%) & $\begin{array}{l}\text { Mean Abs } \\
\text { deviation }\end{array}$ & Mean squared error & AWR (\%) \\
\hline Black African & 6.607 & 68.988 & 69.64 & 9.741 & 140.346 & 41.07 \\
\hline White African & 6.734 & 71.613 & 71.43 & 8.650 & 113.181 & 55.36 \\
\hline Japanese & - & - & - & 50.868 & 2652.699 & 0.00 \\
\hline Present study & 6.550 & 62.834 & 76.79 & 7.185 & 72.318 & 71.43 \\
\hline
\end{tabular}

Unit in centimetre $(\mathrm{cm})$

AWR represents the accuracy percentage of estimated stature within SEE range compared to actual stature

with extensive degree of decomposition whereby positive identification may not be performed through facial recognition or fingerprint detection as well as the tissue and bone cleaning may be time consuming. This may require CT data can be extracted for measurements and even apply the concept of virtual anthropology for biological profiling. Bone measurement by virtual method was highly accurate and reliable as in conventional dry bone measurement method Normaizatul et al. (2019).

The asymmetry of the pelvis is mainly due to Krishan et al. (2010) concludes that there is a higher possibility of obtaining erroneous results while estimating stature from those body dimensions which show statistically significant bilateral asymmetry when formula developed from one side is used on the other side. Future application that using the regression formulae generated from this study has to follow the similar methodology. This was consistent with Kurki (2017) whereby pelvic girdle was bilaterally asymmetry due to multiple selective factors including obstetrics, bipedal locomotion and environmental factors such as biomechanical loading effect.

As mentioned in Lai et al. (2020), the regression formulae for both transverse diameter of S1 body (P2S) and sacral height (P5S) that had been generated from previous studies on Africans by Pininski and Brits (2014) and Japanese by Torimitsu et al. (2017) were applied and 
Table 13 Correlation and regression statistics for combination of pelvic and sacral morphometric against stature according to sex

\begin{tabular}{|c|c|c|c|c|c|c|c|}
\hline $\operatorname{Sex}(N)$ & Regression formula & SEE & $R$ Value & $R$ Square & $\begin{array}{l}\text { Adjusted } \\
R \text { Square }\end{array}$ & F Value & $p$ value \\
\hline $\begin{array}{l}\text { M } \\
179\end{array}$ & $\begin{array}{l}76.332+2.539^{*} \mathbf{P} 1 \mathbf{S}+1.885^{*} \mathbf{P} 3 \mathbf{S}+0.123^{*} \mathbf{P} 4 \mathbf{S}+0.670^{*} \mathbf{P} 5 \mathbf{S}+2.893^{*} \mathbf{P} 6 \mathbf{S}+2.533^{*} \\
\mathbf{P 7 S}+0.289^{*} \mathbf{I 3 S}\end{array}$ & 6.551 & 0.522 & 0.273 & 0.243 & 9.154 & $<0.001$ \\
\hline $\begin{array}{l}F \\
168\end{array}$ & 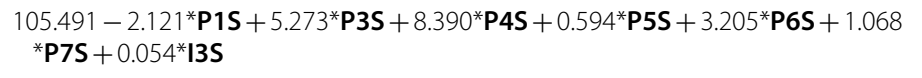 & 6.239 & 0.538 & 0.291 & 0.260 & 9.374 & $<0.001$ \\
\hline $\begin{array}{l}M \\
181\end{array}$ & $\begin{array}{l}59.345-0.305^{*} \mathbf{P} 1 \mathbf{P}+0.979^{*} \mathbf{P} 2 \mathbf{P}+0.867^{*} \mathbf{P} 3 \mathbf{P}-1.874^{*} \mathbf{P} 4 \mathbf{P}+1.877^{*} \mathbf{P} 5 \mathbf{P}+3.419^{*} \\
\mathbf{P 6 P}+1.288^{*} \mathbf{P} 7 \mathbf{P}-0.886^{*} \mathbf{P} 8 \mathbf{P}\end{array}$ & 5.358 & 0.718 & 0.516 & 0.493 & 22.922 & $<0.001$ \\
\hline $\begin{array}{l}F \\
167\end{array}$ & $\begin{array}{l}62.097-0.630^{*} \mathbf{P} 1 \mathbf{P}+0.629^{*} \mathbf{P} 2 \mathbf{P}+1.679^{*} \mathbf{P} 3 \mathbf{P}+2.307^{*} \mathbf{P} 4 \mathbf{P}+0.805^{*} \mathbf{P} 5 \mathbf{P}+2.437^{*} \\
\mathbf{P} 6 \mathbf{P}+1.792^{*} \mathbf{P} 7 \mathbf{P}+1.900^{*} \mathbf{P} \mathbf{P}\end{array}$ & 5.475 & 0.676 & 0.458 & 0.430 & 16.662 & $<0.001$ \\
\hline $\begin{array}{l}M \\
178\end{array}$ & $\begin{array}{l}54.105-0.836^{*} \mathbf{P} 1 \mathbf{S}+0.193^{*} \mathbf{P} 3 \mathbf{S}+0.093^{*} \mathbf{P} 4 \mathbf{S}-0.202^{*} \mathbf{P} 5 \mathbf{S}-0.470^{*} \mathbf{P} 6 \mathbf{S}+0.980^{*} \mathbf{P} \\
\mathbf{7 S}+0.1066^{*} \mathbf{I S S}-0.209^{*} \mathbf{P} \mathbf{P}+1.445^{*} \mathbf{P} 2 \mathbf{P}+1.052^{*} \mathbf{P} 3 \mathbf{P}-1.888^{*} \mathbf{P} 4 \mathbf{P}+1.645^{*} \mathbf{P} 5 \\
\mathbf{P}+3.173^{*} \mathbf{P} 6 \mathbf{P}+1.582^{*} \mathbf{P} 7 \mathbf{P}-0.159^{*} \mathbf{P} \mathbf{P}\end{array}$ & 5.412 & 0.726 & 0.527 & 0.483 & 12.040 & $<0.001$ \\
\hline $\begin{array}{l}F \\
167\end{array}$ & $\begin{array}{l}58.928-0.273^{*} \mathbf{P} 1 \mathbf{S}+1.311 \mathbf{P} 3 \mathbf{S}+1.481 * \mathbf{P} 4 \mathbf{S}+0.429^{*} \mathbf{P} 5 \mathbf{S}-0.958^{*} \mathbf{P} 6 \mathbf{S}-1.418^{*} \mathbf{P} \\
\mathbf{7 S}+0.113^{*} \mathbf{I S S}-0.574^{*} \mathbf{P} \mathbf{P}+1.142^{*} \mathbf{P} \mathbf{P} \mathbf{P}+1.516^{*} \mathbf{P} 3 \mathbf{P}+3.092^{*} \mathbf{P} 4 \mathbf{P}+1.288^{*} \mathbf{P} 5 \\
\mathbf{P}+2.047^{*} \mathbf{P} 6 \mathbf{P}+1.781^{*} \mathbf{P} \mathbf{P}+2.586^{*} \mathbf{P} \mathbf{P}\end{array}$ & 5.481 & 0.693 & 0.480 & 0.429 & 9.304 & $<0.001$ \\
\hline
\end{tabular}

Unit in centimetre $(\mathrm{cm})$

SEE represents standard error of estimation for the generated regression formula; $R$ value represents the Pearson correlation coefficient; Sig. value represents the significant values of the regression ANOVA corresponding to the F value

tested by using the similar holdout subjects compared to the formula in this study. African formulae tended to overestimate based on both parameters (P2S \& P5S) and Malaysia formulae generated from this study produced lower MAD and MSE with higher accuracy within SEE range as summarised in Table 12. Estimated stature based on Japanese formulae were totally out of the range compared to the actual stature. Hence, this had validated that the population-specific formula generated from this study should only be applied to the Malaysian population. Other that these two parameters, there was no any other similar pelvic morphometric that could be comparable with this study.

In overall comparison, pelvic morphometric (Table 11) was generally a better stature estimator compared to sacral morphometric (Table 9) that concurred with Giroux and Wescott (2008) and Torimitsu et al. (2015). This could be due to the locality of the bigger pelvic bones especially ilium height as part of the whole-body stature correlates better compared to sacral bones. In addition, Table 13 showed that the combination of pelvic parameters, sacral parameters and its indexes had contributed to a higher correlation regression coefficient compared to their respective individual estimation in both sexes.

Table 13 also showed that stature correlation and regression coefficient for pelvic morphometric were better in males compared to females which was supported by previous studies (Barbara and Philipp 2015; Pelin et al. 2005; Torimitsu et al. 2014, 2015). However, the generated formulae for overall combined sex as shown in Tables 9 and 11 could be better than formulae according to separate sex in stature estimation. The recommendation of apply the formulae of combined sex for stature estimation in the cases of unknown bodies. The combination of pelvic parameters, sacral parameters and indexes had contributed to a higher correlation regression coefficient.

\section{Conclusions}

The auricular lengths (P6S), ilium dimensions (P5P \& $\mathrm{P} 6 \mathrm{P}$ ) and acetabulum dimensions (P7P \& P8P) were the most useful stature estimator at $R>0.5$. Regression formula was totally dependent on the study population in their respective studies for each individual parameters and indexes being applied. Combination of pelvic parameters, sacral parameters and its indexes had contributed to a higher correlation regression coefficient and smaller standard error of estimation compared to their respective individual estimation. In overall comparison, pelvic morphometric was generally a better stature estimator compared to sacral morphometric. The population-specific formula generated from this study should only be applied within the Malaysian population including Malay, Chinese and Indian. To conclude, this population-specific study based on pelvic girdle among Malaysian helps to improve the existing references for Forensic Anthropologists and Forensic Radiologists to perform stature estimation especially when incomplete human remains are discovered. In the future, researchers of a similar area of interest are recommended to explore more on into other body parts to complement the whole-body stature estimation methods. 


\section{Abbreviations}

3D: Three dimensional; CT: Computed tomography; DICOM: Digital Imaging and Communications in Medicine; FMIS: Forensic Medicine Information System; HKL: Kuala Lumpur Hospital; MAD: Mean absolute deviation; MRI: Magnetic resonance imaging; MSE: Mean squared error; NIFM: National Institute of Forensic Medicine; PACS: Picture Archiving and Communication Systems; PAS: Patient Appointment System; SEE: Standard of estimation error; TEM: Technical error of measurement.

\section{Acknowledgements}

We would like to thank the Director General of Health Malaysia for this permission to publish this article. Also, we would like to express our gratitude to Kuala Lumpur Hospital (HKL) for giving opportunity the use of resources throughout the research. In particular the Medical Research Ethics Committee (MREC) of the Ministry of Health $(\mathrm{MOH})$ for the ethics approval and permission to conduct the research. Last but not least, a great appreciation to forensic scientific officers, radiographers and staff nurse from the HKL for commitment, patience, and involvement in overcoming numerous obstacles while conducting the research and observer analysis.

\section{Authors' contributions}

LPS contributed to the conceptualization, methodology, software, validation, formal analysis, investigation, resources, data curation, writing of the original draft, writing of the review and editing, visualization, and project administration. MHMN contributed to the methodology, writing of the review and editing, validation, supervision and resources. NA contributed to the methodology, writing of the review and editing, supervision and resources. All authors read and approved the final manuscript.

\section{Funding}

We declare that the authors have no any research funding obtained for this original research article.

\section{Availability of data and materials}

Date will not be shared for public access and password protected as kept by the principal investigators.

\section{Declarations}

\section{Ethics approval and consent to participate}

This research has obtained ethical approval with the reference number KKM. NIHSEC.P18-2350(7) and registered under National Medical Research Registry (NMRR-18-3132-44576), Ministry of Health, Malaysia. Consent to participate is not applicable since retrospective data acquired under ethics approval by the Medical Research Ethics Committee of Ministry of Health, Malaysia.

\section{Consent for publication}

Not applicable.

\section{Competing interests}

The authors declare that they have no known competing financial interests or personal relationships that could have appeared to influence the work reported in this paper.

\section{Author details}

${ }^{1}$ Institute of Forensic Medicine Malaysia, Kuala Lumpur Hospital, Kuala Lumpur, Malaysia. ${ }^{2}$ Radiology Department, Kuala Lumpur Hospital, Kuala Lumpur, Malaysia.

Received: 21 April 2021 Accepted: 1 August 2021

Published online: 09 August 2021

\section{References}

Barbara F, Philipp M (2015) Covariation between human pelvis shape, stature, and head size alleviates the obstetric dilemma. Proc Natl Acad Sci USA 112(8):5655-5660. https://doi.org/10.1073/pnas.1420325112

Boulay C, Tardieu C, Bénaim C, Hecquet J, Marty C, Prat-Pradal D et al (2006) Three-dimensional study of pelvic asymmetry on anatomical specimens and its clinical perspectives. J Anat 208(1):21-33. https://doi.org/10. 1111/j.1469-7580.2006.00513.x

Garvin HM, Severa K (2019) An alternative method to using a mandibulometer. J Forensic Sci. https://doi.org/10.1111/1556-4029.14026

Giroux CL, Wescott DJ (2008) Stature estimation based on dimensions of the bony pelvis and proximal femur. J Forensic Sci 53(1):65-68. https:// doi.org/10.1111/j.1556-4029.2007.00598.x

Goto R, Nicholas MTCG (2007) Precision of measurement as a component of human variation. J Physiol Anthropol 26(2):253-256

Hakki MK, Osman C, Ahmet H, Banu A (2011) Total body height estimation using sacrum height in Anatolian Caucasians: multidetector computed tomography-based virtual anthropometry. Skeletal Radiol 40:623-630. https://doi.org/10.1007/s00256-010-0937-x

Jamaiyah H, Geeta A, Safiza M, Khor G, Wong N, Kee C et al (2010) Reliability, technical error of measurements and validity of length and weight measurements for children under two years old in Malaysia. Med J Malaysia 65(Suppl A):131-137

Kanika S, Rajan KS, Gurdeep K, Gaurav S (2011) Role of sacrum in sexual dimorphism: a morphometric study. Journal of Indian Academic Forensic Medicine 33(3):206-210

Khoo LS, Mohd Shah M (2014) Postmortem computed tomography. http:// www.myhealth.gov.my/en/postmortem-computed-tomography/ Accessed 18 Mar 2019

Kotarinos RK (2016) Chapter three: Musculoskeletal pelvic anatomy. In: Hoyte L, Damaser M (eds) Biomechanics of the female pelvic floor. Academic Press, pp 53-87

Krishan K, Kanchan T, John AD (2010) A study of limb asymmetry and its effect on the estimation of stature in forensic case work. Forensic Sci Int 200(181):e1-5

Kurki HK (2017) Bilateral asymmetry in the human pelvis. Anat Rec 300(4):653-665

Lai PS, Mohamad Helmee MN, Nurliza A, Helmi H (2020) Stature estimation of the Malaysian population based on sacrum CT scans. Egypt J Forensic Sci 10(18):1-11. https://doi.org/10.1186/s41935-020-00192-5

Lia B, Noreen CT, Andrea M, Stephen JL (2013) Global geometric morphometric analyses of the human pelvis reveal substantial neutral population history effects even across sexes. PLoS ONE 8(2):e55909:5590155910. https://doi.org/10.1371/journal.pone.0055909

Linda LK (2006) Fundamentals of forensic anthropology, 1st edn. Wiley Mahakkanukrauh P, Khanpetch P, Prasitwattanseree S, Vichairat K, Case DT (2011) Stature estimation from long bone lengths in a Thai population. Forensic Sci Int 210(1-3):279.e271-279.e277. https://doi.org/10.1016/j. forsciint.2011.04.025

Megan KM, Ann HR (2013) Stature estimation. In: Elizabeth AD, Megan KM (eds) Research methods in human skeleton biology, 1st edn. Academic Press, pp 151-180

Normaizatul Al, Nurliza A, Mohamad Helmee MN, Lai PS, Mohamed Swarhib S, Faridah MN (2019) Accuracy and reliability of virtual femur measurement from CT scan. J Forensic Leg Med 63:11-17. https://doi.org/10.1016/j.jlm. 2019.02.010

Özaslan A, İşcan MY, Özaslan IN, Tuğcu H, Koç S (2003) Estimation of stature from body parts. Forensic Sci Int 132(1):40-45. https://doi.org/10.1016/ S0379-0738(02)00425-5

Pelin C, Duyar I, Kayahan EM, Zagyapan R, Agildere AM, Esra A (2005) Body height estimation based on dimensions of sacral and coccygeal vertebrae. J Forensic Sci 50(2):294-297. https://doi.org/10.1520/JFS2004010

Perini TA, Oliveira GL, Ornellas JS, Oliveira FP (2005) Technical error of measurement in anthropometry. Revista Brasileira De Medicina Do Esporte 11(1):81-85

Pininski M, Brits D (2014) Estimating stature in South African populations using various measures of the sacrum. Forensic Sci Int 234:182.e181-182.e187. https://doi.org/10.1016/j.forsciint.2013.08.030

Shreekrishna H, Yatiraj S, Vijayakumari N (2013) Credibility of various indices of sacrum in identification of sex of sacrum. Int J Med Toxicol Forensic Med 3(2):58-63. https://doi.org/10.22037/ijmtfm.v3i2(Spring).3598

Standring S (2015) Gray's anatomy international edition: the anatomical basis of clinical practice, 39th edn. Elsevier

Torimitsu S, Makino Y, Saitoh H, Ishii N, Hayakawa M, Yajima D et al (2014) Stature estimation in Japanese cadavers using the sacral and coccygeal length measured with multidetector computed tomography. Leg Med 16(1):14-19. https://doi.org/10.1016/j.legalmed.2013.10.003 
Torimitsu S, Makino Y, Saitoh H, Sakuma A, Ishii N, Hayakawa M et al (2015) Stature estimation in Japanese cadavers based on pelvic measurements in three-dimensional multidetector computed tomographic images. Int J Legal Med 129(3):633-639. https://doi.org/10.1007/s00414-014-1000-6

Torimitsu S, Makino Y, Saitoh H, Sakuma A, Ishii N, Yajima D et al (2017) Sex determination based on sacral and coccygeal measurements using multidetector computed tomography in a contemporary Japanese population. J Forensic Radiol Imaging 9:8-12. https://doi.org/10.1016/j. jofri.2017.01.001

Wiley P (2016) Stature estimation. In: Soren B, Douglas HU (eds) Handbook of forensic anthropology and archaeology, 2nd edn. Taylor \& Francis, pp 308-321
Wilson RJ, Nicholas PH, Lee MJ (2010) Evaluation of stature estimation from the Database for Forensic Anthropology. J Forensic Sci 55(3):684-689. https:// doi.org/10.1111/j.1556-4029.2010.01343.x

Zhan MJ, Fan F, Qiu LR, Peng Z, Zhang K, Deng ZH (2018) Estimation of stature and sex from sacrum and coccyx measurements by multidetector

computed tomography in Chinese. Leg Med 34:21-26. https://doi.org/10. 1016/j.legalmed.2018.07.003

\section{Publisher's Note}

Springer Nature remains neutral with regard to jurisdictional claims in published maps and institutional affiliations.

\section{Submit your manuscript to a SpringerOpen ${ }^{\circ}$ journal and benefit from:}

- Convenient online submission

- Rigorous peer review

- Open access: articles freely available online

- High visibility within the field

- Retaining the copyright to your article

Submit your next manuscript at $\boldsymbol{\nabla}$ springeropen.com 